Articles

6-2012

\title{
Faculty in the Hinterlands: Cultural Anticipation and Cultural Reality
}

Pamela L. Eddy

College of William \& Mary, pamela.eddy@wm.edu

Jeni Hart

University of Missouri, hartjl@missouri.edu

Follow this and additional works at: https://scholarworks.wm.edu/articles

Part of the Higher Education Commons, and the Social and Philosophical Foundations of Education Commons

\section{Recommended Citation}

Eddy, Pamela L. and Hart, Jeni, "Faculty in the Hinterlands: Cultural Anticipation and Cultural Reality" (2012). Articles. 65.

https://scholarworks.wm.edu/articles/65

This Article is brought to you for free and open access by W\&M ScholarWorks. It has been accepted for inclusion in Articles by an authorized administrator of W\&M ScholarWorks. For more information, please contact scholarworks@wm.edu. 


\begin{abstract}
Using qualitative inquiry, this paper employs a cultural lens to explore the work life experiences of faculty who work in smaller higher education administration programs in institutions that are not high-level research universities. The research focus included understanding how participants' made sense of the institutions in which they worked and the consequences of that for their lives.

Implications for the field of higher education administration, faculty work, and graduate socialization are examined. Ultimately, this research suggests that a single model of faculty work life identity drawn using a research institutional prototype does little to support all faculty members, many of whom work in markedly different institutions.
\end{abstract}




\section{Faculty in the Hinterlands: Cultural Anticipation and Cultural Reality}

Training graduate students for faculty positions assumes students are going to work at institutions similar to those in which they earned their doctorates - predominantly research universities with very high research expectations. This narrow focus, however, does not account for cultural differences between institutional types nor the impact of these cultures on faculty work (Finnegan 1993). The reality is that many students accept faculty positions at a variety of institutions that are markedly different and pointedly lower on the Carnegie classification scale (see http://classifications.carnegiefoundation.org/ for details about classifications). Work in such organizations, sometimes in remote geographical locations, generally involves smaller departments supporting more teaching responsibilities, more administrative work, and more service—sometimes without a significant reduction in expectations for scholarship In fact, as the accountability movement increases (Field 2006) and external funding support decreases for institutions of all types, research demands, especially those tied to grant dollars and high indirect costs, escalate for all faculty (Aldersley 1995; Austin 2002; Fairweather 1996; Toma 2009), but the other demands remain the same.

While new faculty may have the requisite research skills for their positions, for those hired at institutions other than doctoral research extensive universities ${ }^{1}$, graduate school may not have fully prepared them for other job demands. Faculty socialization (Austin 2002; Wulfe and Austin 2004) and new faculty concerns regarding requirements in the professoriate (Austin 2003; Menges 1999; Sorcinelli 2002) underscore how graduate students form impressions and expectations of (i.e.,

\footnotetext{
${ }^{1}$ As we categorize institutions from this point on, we will refer to the Carnegie Classification used at the time the data were collected for this study.
} 
culturally anticipate $^{2}$ ).a faculty career. The research culture in which most faculty members are trained affords a limited view of faculty life. For example, faculty working in smaller programs, including those who work at "direction” universities (e.g., Northern Michigan University, University of Central Missouri, Eastern Carolina University), often have heavier teaching and advising loads, salaries lower than at other universities, and have responsibilities for ancillary activities like program building (Rauch 2005; VanderStaay 2005).

The concept of working in a smaller, more remote program conjures up the image of programs located in less populated, more isolated regions at institutions with fewer resources (Eddy and Murray 2007). Little research has been conducted to explore what such isolation means to faculty or how faculty members are prepared to work in such a setting. To address this gap in the literature, we interviewed faculty who worked at institutions not classified as doctoral research extensive in cities with a population of fewer than 75,000 and in units with only two or fewer fulltime tenure track faculty. The purpose of the study was to better understand how faculty in the field of higher education working in small, geographically remote institutions experienced their work lives given their cultural anticipation of faculty work. Faculty in doctoral programs and academic administrators in these remote programs can use the findings of this research to align faculty work with institutional mission and to better support faculty members. Likewise, international universities can learn strategies to create structures that support the development of smaller academic programs at geographically rural or isolated institutions.

\section{Review of the Literature}

Few researchers have studied how faculty experience working in smaller programs in any field or discipline. However, the research that has been conducted most often portrayed smaller

\footnotetext{
${ }^{2}$ Specifically, we define cultural anticipation as expectations individuals have developed of the values, beliefs, and attitudes about a particular setting and what they assume life will be like in that setting. For the purposes of this paper, these assumptions and expectations are developed through socialization experiences, often in graduate school.
} 
programs as geographically isolated institutions in rural communities, and this geographic isolation often led to faculty being one of only a very few members of an academic department. Researchers have positioned their studies based upon the rural nature of the campuses, but have learned through their investigation that the faculty members' departmental culture on these campuses can also be isolating.

Finnegan (1993) argued that the academic labor market is segmented by institutional type. She further posited that faculty careers evolve given the external labor market, institutional choices of hiring colleges, and by the faculty members already on staff and those hired after them. In the cases presented in Finnegan's research at comprehensive universities, the impact of researchteaching tensions influenced the generations of faculty on staff differently. The bar for tenure and promotion rose over time, placing additional pressures on new faculty and disadvantaging more senior faculty whose scholarship languished as they devoted their energies to creating programs and teaching. A new generation of faculty has been hired since Finnegan conducted her research and the external climate of higher education has shifted. Indeed, some assert the culture has transformed (Gappa, Austin, and Trice, 2006). Rhoades (2009) argues that the tenure process for new faculty is used to leverage an increase in institutional rankings and necessitates doing more of everything - in particular more publishing in high-ranking journals - to help increase institutional prestige. Understanding the impact of these shifting patterns on faculty members in smaller, remote programs provides insights to program coordinators, hiring committees, those interested in doctoral preparation, and individual faculty as they contemplate their career options.

Qualitative research of faculty from a variety of disciplines in rural and metropolitan Australia found that faculty who worked on a rural campus experienced work life differently than their metropolitan counterparts (Ellis, Boxall, Dollard, and Sawyer, 1999; Ellis, Sawyer, Dollard, and Boxall, 2002). These faculty members saw that part of their role was localized in nature. 
Instead of focusing education for students who intend to work in the national or international sectors, they were challenged to teach with the purpose of enhancing the rural and regional economies. The authors put little emphasis on the experiences of the metropolitan faculty, except in the context of how they understood the lives of rural academics (overwhelmingly they concentrated on perceived negatives of working on a rural campus by these metropolitan faculty). Instead, and as we do, the authors described the experiences of rural faculty.

In both studies, the researchers reported that rural faculty experienced trade-offs in their work (Ellis et al., 1999; Ellis et al., 2002). While they described heavy teaching and student contact loads, limited resources in terms of research, large numbers of meetings, and limited amenities usually associated with living in a larger community, the rural faculty also shared that their jobs had great flexibility in terms of methods of teaching delivery, opportunities to teach a breadth of courses, occasions to conduct cross-disciplinary research, limited commuting to campus, and perceptions of a safe and welcoming community. Ultimately, the range of perceptions among those who worked on rural campuses resulted in two camps - those who want to stay forever and those who wanted to leave that environment as quickly as possible. However, the researchers did little to theorize why these rural faculty members felt the way they did nor whether there were unique characteristics for those who felt positively about their faculty experiences and for those who felt more critical of their faculty roles on a rural campus.

Faculty of color face additional feelings of isolation in rural locales (Bennefield, 1999). Not only are they isolated from colleagues in a broad sense, they were isolated from a community of color. In Bennefield's (1999) research, the faculty who tended to be most satisfied on rural campuses were those who had partners and families and those who solely focused on work. The construction of faculty work as managed professionals (Rhoades 1998) sets the stage for an academic life overtaken by work (Taylor 2008) with little balance (Rhoades 2006). Although recent 
research on academic work (O’Meara, Terokay, and Neumann, 2008) challenges the narrative of constraint regarding faculty work and underscores a need to focus instead on the passion driving faculty interests (Neumann 2009), little attention is paid to the role of socialization into and anticipation of the faculty work life in a smaller community.

Faculty members in rural areas often face demands that differ from their metropolitan counterparts. For instance, Spall and Norum (2002) used autoethnogrphy in their research and shared frustrations with the nature of academic life on their rural campuses that included expectations of being in the office every day, high demands for committee work, teaching what they were told to teach, and having to coordinate and build academic programs by themselves. Yet, along with those frustrations, their academic identities were shaped and inspired by students, reinforcing that there are positive aspects to working in a rural setting. Larger studies mirrored these findings (Murray 2005; Wilson 2000) and reinforced a dichotomy of faculty in rural areas of either lifers or leavers. Yet, the differences were not as clearly delineated as the findings would suggest. Instead, a third category (which was also the largest category) emerged of undecided faculty who identified some met and some unmet expectations in their work lives and as a result were uncertain about whether they wanted to stay in the rural environment or leave. Clearly, this research points to the multifaceted, and sometimes disparate, experiences of rural faculty life.

\section{Conceptual Framework}

Understanding faculty culture can provide a lens to position faculty work. Cultural anticipation of faculty work begins during graduate student socialization (Austin 2002). New faculty members bring concepts of life as a faculty member to their positions. These ideas and expectations are based upon their observations of faculty work during their doctoral programs, which predominantly occur at research extensive universities. Thus, when new faculty move to an 
institution unlike the one from which they graduated and were socialized (e.g., a rural teaching university), often their anticipated understanding of faculty life is challenged.

Using a cultural perspective, Wolfe and Strange (2003) determined, first, rural faculty wear many hats - their jobs were complex, particularly when they were members of a one-person department. Second, although the faculty experienced a great deal of autonomy in their jobs, their work took a toll on them due to the excessive teaching and service demands. Third, Wolfe and Strange noted the influence of discipline on faculty culture. Although other scholars who have researched rural faculty purposefully included faculty from more than one discipline or field of study, Wolfe and Strange are unique in discussing the impact of specific disciplines on faculty, finding that the academic field also influences how faculty experience their lives in a rural locale. They also found disadvantages and advantages to working in a rural community. However, they purported that the culture, both for the faculty and for the students, of the campuses under investigation was what higher education was intended to be-an environment that offers programs that are responsive to student and community needs and a faculty that are student-centered (Neumann 2009; Wolfe and Strange, 2003).

Understanding more about the contextual influence of rural institutions, coupled with the size of these institutions, provide a unique lens for analysis to consider the lived experiences of faculty working in small, remote programs. In the end, the existing research on faculty working on rural campuses, or in small programs, used a variety of qualitative approaches to explore the work lives of these faculty members. However, few of the studies considered the expectations faculty had for their work in small, rural regions. Wolfe and Strange's (2003) research provided a conceptual foundation that integrates the perspective of faculty culture from which the current study drew. We paid particular attention to work role expectations and the influence of institutional, departmental, and disciplinary culture on the experiences of the faculty interviewed. 


\section{Methods}

For this study, we concentrated on higher education administration programs, including those that focus on student affairs administration and college student personnel. We focused this research on one distinct field of study, namely higher education administration. This allowed for an understanding of faculty culture that was not complicated by disciplinary and field differences. In addition, the curricula in programs of higher education often focus on faculty work. As such, we assumed the participating faculty likely had an enhanced understanding of and preparation for work as faculty members.

There were approximately 194 programs of higher education and student affairs administration in the United States, based upon a compilation of the data bases of such programs available from the Association for the Study of Higher Education (ASHE) and the ACPA—College Student Educators International at the time the data for this study were gathered. A research team comprised of four members purposively selected participants based upon a number of criteria. First, we focused on institutions located in cities with a population of fewer than 75,000 . Second, we looked at programs that were not housed in institutions classified as doctoral research extensive universities according to the 2000 Carnegie classification schema. Finally, we chose higher education and student affairs programs with two or fewer full-time faculty. Thirty-four programs in 19 states met these criteria. All 52 faculty members working in these programs were invited to participate in this study. Subsequently, faculty from a total of 10 of the programs indicated they did not meet the study criteria (e.g., their programs disbanded or added more faculty than reported to ASHE or ACPA), and one other declined participation, leaving a possible pool of 36 faculty members from 23 programs. We contacted these individuals via email and 20 faculty members at 16 institutions agreed to participate. Nearly all the participants were untenured, but on the tenure 
track, allowing them to more easily remember their doctoral preparation as it relates to their current position.

Both telephone and face-to-face interviews were conducted with the individual faculty members using a semi-structured interview protocol (Kvale 1996; Rubin and Rubin, 1995) that was guided by the literature reviewed and the conceptual framework. This study was an instrumental case study (Merriam 1998) bounded by higher education and student affairs faculty members who worked in small programs in rural institutions. In conducting this research we also adapted design elements of phenomenology in order to focus on the meaning of the lived experience (Creswell, 1998) of working in smaller programs, in more remote locations. Interviews were recorded with consent and transcribed verbatim. During one interview, when the tape recorder malfunctioned, the interviewer took notes that were subsequently typed and member checked by the participant for accuracy.

Geertz (1993) noted that researchers and participants are equally involved in creating understanding of the findings. Our positionality as cultural insiders provided us with the ability to establish rapport with our participants (Ganga and Scott, 2006). Specifically, each member of the research team worked or was working in a small higher education program in a rural location. Because we brought emic perspectives to the research, we were particularly careful to bracket our assumptions during data analysis (Creswell, 1998).

To begin the analysis, the research team discussed coding strategies and initial themes that emerged from their field notes and journals. Based upon our discussion, we agreed to initially code the data based upon the traditional elements of faculty work: research, teaching, and service to the profession. All research team members coded each interview independently using this coding framework and then compared the emergent themes among the team members to identify any discrepancies. In the event of disagreement regarding a coded passage, the team reviewed the 
transcript and through consensus determined the most salient themes. Ultimately, trustworthiness of the patterns and themes that emerged from the coding was enhanced due to the combination of independent and consensus coding strategies, resulting in triangulation among the researchers. Credibility and dependability of the overall study were enhanced by the use of member checking, peer debriefing, and using thick description to present and discuss findings (Denizen and Lincoln, 2000).

\section{Findings}

The findings show that faculty culture in small programs in the hinterlands ${ }^{3}$ is not uniform, despite looking at faculty members who are all from the same field of study. Instead, their lived experiences are multifaceted and create a picture that is most often unlike that for which they were socialized. The data centered on the broad theme, Institutional Sense-making. We also explored several sub-themes related to institutional sense-making. Specifically, we described the issues of expectations, cultural disequilibrium, and isolation and autonomy as they contribute to how faculty make sense of their work settings and the implications of being in that setting. We note that some of these same issues are relevant for faculty at other types of institutions, and possibly in other disciplines and fields. However, the findings below uniquely describe how the higher education faculty with whom we spoke understood their work lives in their particular context.

\section{Institutional Sense-making}

Faculty chose their current positions and institutions for a variety of reasons and the theme of institutional sense-making clearly emerged as central to how faculty understood their work lives in the hinterlands. Institutional sense-making involved consideration of the culture of the institution and department, as well as the location of the institution. For some of our participants, culture

\footnotetext{
${ }^{3}$ We use the term "hinterlands," not as a pejorative term, but rather as a descriptive term to capture the essence of a region that is outside a metropolitan or urban center. In fact, some of our participants used this term independently and with endearment.
} 
contributed to their decision of whether to work in a rural college. The full extent of the cultural impact, however, was not always apparent at the time of accepting the job offer. Cultural differences relative to the research universities in which faculty members were trained centered on size of the departments, teaching load, and administrative expectations.

Faculty members' motivations regarding their initial application for the faculty position found roots in both intentional and serendipitous decision making. They made purposeful choices based on the small-town nature of the university's location, family, and the desire to focus more on teaching and interactions with students. One participant commented, "My wife and I have two sons and we just decided we needed to be in a different culture, a smaller town." The convenience of the location with respect to supporting spousal careers and maintaining stability for children was a key reason for institutional choice for nearly half of our participants.

The majority of participants did not find their location in a smaller region to be an overwhelming obstacle to job satisfaction and crafting a professional life. As one faculty member commented,

Geographically, where my institution is placed, it gives me the best of a couple of conditions to some major metropolitan areas within a 40-45 minute drive but I am still able to live in a rural area. My commute to work is seven minutes; I am able to move around the area quickly.

The alternative of living in large urban areas was not viewed as an attractive option. According to one faculty,

The bias there is to assume those [urban areas] are destinations of choice. Quite honestly, many of us in the Midwest, would not say those are destinations of choice. I would say, and I will speak for myself, that those would be the last places I would want to live and work. 
In addition, for some, the rural locales were similar to areas in which the participants had grown up, thus the culture felt quite familiar.

The smaller departments in which these programs were housed were seen as offering potential for the participants. One faculty member said,

I believe in community so much and I really believe we need to know the people we work with and contribute to really making this a good place. I think that is the one thing that is really attractive about being here because there is a lot of potential. There are some very fine people.

Relationships with students were key factors in creation of community and professional engagement as well. A focus on students propelled many faculty members to seek work and stay in rural institutions with cultures that focused on students and teaching.

Several faculty members did not see the small size of their program or community as a disadvantage, but rather as a key reason for their institutional choice. One participant tied in his past experience in order to make sense of his new location. He noted, "I think the biggest reason for selecting this institution was my personal and professional history and really my own selfawareness. Having a very well-defined vision for the kind of environment I wanted for work-both autonomy and support." The small size of the unit and college allowed for the key items this faculty member sought in a career.

Expectations. For some participants, the initial move to a smaller city or region and a smaller program took more adjustment based on their expectations from previous experiences and from graduate school. One faculty member noted,

It was a huge surprise. What I was told, an understanding I got in my graduate program, you come in they give you a percentage of money to start up your research agenda and $\$ 2,500$ 3,000 every year so you can get moving. Then they also put...your profile in [a] computer 
[database] to match your interest with available national grant funds and then work with you to build your research to support this. But I got none of that-zilch.

This faculty member was socialized to expect his new faculty position would be modeled on those “normal' to a research university. This cultural anticipation created a disconnect with the actual faculty work. Still others expected to have a pick of faculty positions at research universities because they graduated from one of the top 10 higher education programs in the country.. As one noted,

I think the year I graduated we had four graduates looking for faculty positions. We thought you went there and all of a sudden the red carpet would be rolled out and people were going to be falling all over you and that just was not the case. It was a rude awakening for some because you had been nurtured in this environment where you were thought of as so special and now given that reality check.

Socialization had prepared these faculty members to expect or even feel entitled to faculty positions at well-funded research institutions, often to the exclusion of considering other more teaching oriented openings.

Participants reflected that faculty from their doctoral programs often held expectations for them to be hired by a similarly situated research extensive university, and such a placement was a measure of ultimate success for both the participant and their doctoral advisor. One person noted, I could probably say that I disappointed most of my faculty by taking the job that I did. I was being groomed to be able to function well in that environment [research extensive university], which is certainly not the environment that I walked into.

From a preparation program perspective, the measure of success included graduates who obtained positions at like-type research focused institutions, but the reality of the academic market limited the number of available positions. Amidst this backdrop, graduates also made choices to not seek 
out research positions. As this participant further reflected upon her graduate faculty, she said "they understood why I was doing it [taking the position in the hinterlands], but it's like they thought, you really could do better..."

Despite the views of their mentors, most faculty members interviewed did not construct the image of their current position as second rate or as a consolation prize- even if they decided that the fit was not ideal. Yet others who constructed their choice as "accepting any position" or using the position as a stepping stone exhibited more frustration about their choices. For these faculty members, their expectation was that they would use the rural faculty job to position themselves for a position at a research university in a larger community.

Cultural disequilibrium. Several participants noted differences in cultures between the universities in which they were trained and in which they now found themselves employed. Cultural differences centered on size of the departments, teaching loads, and administrative expectations. One faculty member commented,

Conceptually, it's a really different environment. I came here from [a research extensive university]. At the first faculty meeting when somebody said, well we're down three students and that may be a problem for us, my mouth dropped. I just couldn't imagine that three students or five students represented a significant percentage of any program, but it does here.

Another faculty felt it critical that doctoral programs better prepare those coming to smaller programs to adapt to their surroundings once they arrived. Most participants noted that they felt quite prepared for their faculty roles, particularly concerning the research component. However, one participant said bluntly, "I didn't feel at all prepared to teach." The high teaching loads for participants in this study made teaching an immediate initial challenge. They reported several new course preparations (sometimes as high as six) during their first year. They acquired advisees and 
students at the dissertation stages in their programs well before their counterparts at research universities. Instead of focusing on a few courses to teach in a rotation, they taught more courses and were generalists. Faculty work was constructed more as a commodity in these programs and course offerings were driven by market demands.

Our participants felt orientation processes at their universities were incomplete, neither focusing on teaching nor the institutions' cultures. Rather, they focused on filling out forms and learning about benefits and parking. When available, teaching centers sometimes led workshops to orient new faculty to teaching responsibilities, but no programs included a comprehensive orientation to new faculty roles. Although orientation processes at research universities may be equally lacking focus on key components of faculty work, for those in our study, the need to be oriented to the faculty culture and to network across the college for collaborative research and teaching tips was especially important.

Participants expressed tensions between research, teaching, and practice, and ultimately what comprises faculty work in their hinterland culture. Given the nature of smaller programs, the participants, including new faculty, were often heavily involved in practice (i.e., the administrative roles of program). Time constraints often pitted involvement in practice against time for other responsibilities. However, for some of our participants, these administrative roles were quite familiar and comfortable. In fact, some of our participants found themselves increasingly drawn into committees and other administrative work. One said, "I think it is just a matter of time before I will go back to administration."

Participants' administrative backgrounds were often evident in the type of work they were drawn to on campus. One faculty participant declared, "This is why I have a hard time even at faculty meetings because I don't talk like one [a faculty member] and I don't act like one. I am an administrator." But in many cases, it was the administrative background of the participants that 
made them qualified and attractive faculty hires for their programs. Relative to universities with high expectations for research, administrators are valued candidates for faculty positions given the needs of the programs to tie to practice. The high levels of administrative responsibilities, however, were noted as follows,

It just wears me out. I spend probably--I've been measuring this for the last number of years--and I've spent an average of about 20 to 25 hours a week on administrative [tasks]. Including recruiting students, admission, orientation-orienting the students when they come here-I handle all our financial alumni giving, budget, you know budget kinds of concerns, curriculum changes, adjunct faculty management.

These expectations often led to faculty feeling as if they must prioritize these teaching and service roles above most others. Moreover, the lack of release time or legitimate credit for this work in tenure and promotion for some of the administrative functions was a source of concern for many of the participants.

Those faculty members moving to their position from administration observed a different sort of culture shock. Former student affairs administrators noted the pay cuts they took to take their teaching positions. The years out of the classroom for administrators-turned-faculty resulted in even more time devoted to teaching preparation, particularly in the first years in the classroom. Additionally, during their time as administrators, they were more apt to work in a hierarchical and bureaucratic setting. The academic cultures in which these former administrators now operated were built on faculty autonomy and loose coupling of departments and units. This transition required a different set of skills. Likewise, they were used to a system of annual evaluation based upon clearly delineated job goals. However, faculty tenure processes were often not well articulated and required more years before receiving detailed feedback since tenure was typically not awarded until after 6 years in faculty rank. Further, tenure review committees did not use 
Boyer's (1997) more comprehensive definition of scholarship, thus the time devoted to practice was discounted in tenure packets.

In addition, working in smaller programs often meant higher teaching loads. Typical teaching assignments were three courses in the fall and spring semesters, with additional teaching of one or two classes expected in the summer. By and large, teaching was a focal point for the faculty in this study. One participant said, "I teach everything, you know I teach an overload. Usually at least one semester a year. So for the past two years, I taught nine courses a year. The colleagues I know at Research Is, teach four." The heavy teaching load also meant that faculty members were responsible for a wide variety of courses. One new faculty reflected, "[In my first three years], I have prepped 11 new courses...It might be up to 12 . I also wrote curriculum to create three new courses." The focus on teaching was due to the missions of the universities in which the participants worked and had clear implications for tenure and promotion.

Research demands were perceived as being less onerous relative to research university expectations, but changes in expectations were also common. As one participant noted,

Personally what stresses me out is getting the research and the writing done. I'm a good writer, but I hate to do it though. It is difficult to get that. The multiple demands on time is another thing. For some of our faculty the message they received was, "You can do research, but don't get carried away." In general one or two publications a year.

Others found that the role of research changed over time. According to one participant, When I walked in the door the associate dean said ...you write an article and do a couple of presentations and when you come up for tenure you will be fine. By the time I came up for tenure 5 to 6 years later, we were at a very different place. The provost had written a white paper on scholarship. We were upping the ante as many institutions were. 
As is the case at many institutions, faculty were increasingly asked to apply for and secure grants and external funds. One participant said, "It is becoming more and more difficult not to be involved somehow in trying to gain external dollars." The competing demands of the job resulted in less time for the increasing expectations related to research. Faculty participants believed that their counterparts at research universities received greater resources and support. A faculty member commented,

At Research I institutions, they are wonderfully resourced and you can get most anything that you want, but their expectations are not what I am interested in, particularly, you spend too much time doing things for the tenure and promotion file and not enough doing things with your students or doing things that are just of interest, which may not get you anywhere. Consistent with others' reflections, this faculty member again reinforced the challenges they faced trying to meet competing work demands, interests, and stakeholders.

Isolation and autonomy. For several of our participants, their new faculty roles resulted in personal and professional isolation; however, that isolation also created a certain degree of freedom for them. Some faculty felt isolated both with respect to their more remote location and also within their own departments and institutions. Living in a smaller community meant less access to cultural events, specialty stores, and educational opportunities for children. Small departments offered fewer opportunities for conversations regarding research interests. At the same time, other faculty members pointed out the benefits of cross-departmental collaborations and the ease of access to other departments given the small size of the college community. In addition, isolation also meant that some of these faculty members had great autonomy that allowed them to recruit students, design curriculum, and conduct research without any interference, making a program truly their own. Despite some of the challenges, the small nature of their programs provided the participants with more autonomy and leadership possibilities. 
Regardless of the motivation that brought them to their positions, participants noted elements of isolation. One research participant shared, "It gets isolating very quickly. Other faculty are at a different phase - they are retired and on a second career. Their motivation is different than mine; I'm trying to get myself off the ground." Longer serving faculty members did not experience the extremes of isolation compared to their recently hired peers.

Faculty members reported increased isolation because their small higher education program was housed in larger general educational leadership, counseling, or foundations departments. One person commented, “There's not the same type of understanding of each other's work." Coming [to] a department with multiple (and modestly staffed) academic fields meant few individuals were available for collaboration within the department on research or to serve as peer reviewers for writing.

Being a faculty member in a smaller program meant that participants dealt creatively with issues of isolation. When discovered, partnerships and collaborations were noted as a common solution to address isolation. As one faculty member said, "We couldn't have the program if it weren't for the partnership with the division for student affairs and the educational leadership department." Adjuncts, often sitting university administrators, also augment the teaching staff. A participant noted, “Well, I don't think of myself as a one-man shop. I really don't..... I have got six people who are actively teaching in the program every year." In fact, campus administrators often provided a substantial peer group for our faculty participants. The culture of isolation within the department created the need and opportunity for faculty members to craft different types of working relationships to substitute for the type of operations found in larger units.

Several of the participants who were actively pursuing a research agenda described another source of isolation when departmental colleagues did not value or oftentimes even recognize research success and productivity. One participant noted, 
I [publish] something in the Journal for College Student Development [a highly regarded U.S. journal in the field] and nobody knows because they don't read it. They know I do research because they see me at my computer, you know, or I talk about it but it is not the same nor do they really engage me about it.

Another participant offered,

I learned the first semester that you did not talk about research or the fact that you did research. I can't remember quite what the comment was now precisely, but it was during a department meeting and it became quite apparent that you did not tell people you were doing these things. So, I did not tell people when I had articles published or when I had presentations.

Faculty members at institutions seeking to increase their reputation often placed increased demands on newer faculty, thus the newer faculty participants in this study had more pressures to perform relative to their senior colleagues. This institutional striving behavior led to another form of isolation. Senior faculty members in smaller programs were not immune to these pressures, however, as many were unable to seek promotion since they dedicated so much of their time earlier in their career to service and professional activities versus their own research.

Trying to gain legitimacy from colleagues outside the institution led to a sense of isolation for some faculty. Being housed in smaller programs with fewer resources often meant faculty had less opportunity to attend professional development sessions or conferences. These limits in professional networking served to contribute to frustrations about staying current in the field and in creating and maintaining support outside the institution. Even when faculty had opportunities to attend professional meetings, some reflected upon the marginalization they felt by colleagues at more "prestigious" institutions. One participant said, "So the isolation that I feel is kind of a lack of legitimacy. I have to explain why I'm here, why the program is here, what we are, who we are, that 
we're credible, yes indeed we really are accredited." The constant act of justifying their professional choices, department credibility, and ultimately their personal choices created a strain.

The small nature of the programs in which our faculty participants were housed meant they carried multiple responsibilities and stressors. For those in institutions with a primary focus on undergraduate education, their programs were often marginalized.

We're on the periphery, [our program] is something of the second thought. You know just like when faculty meetings are held, it's always on an afternoon when we start classes at 4:00. All the faculty meetings are always at 3:30. And I can go for like 20 minutes. And that is metaphor for how everything happens here. We really consider [the university] as an undergraduate institution and then it's like yeah, yeah, yeah, those graduate students.

However, the ability to be under the institutional radar was not always viewed as a bad situation. Faculty members were able to take on responsibilities normally not available until later in a career. As one participant noted, "I am functionally the program coordinator and that is a tremendous opportunity for a first-year faculty member.” This same faculty member added, My boss was amazing, giving me autonomy....He has been a tremendous resource....he has allowed me a tremendous amount of freedom and flexibility to put my own flavor on the program and that is another benefit of coming to a smaller institution — that I don't have to become a number that functions in an institution and just have my assignments and just go through my day to day.

The ability to design curriculum and work with smaller groups of students allowed several of the participants to have experiences normally regulated to more senior colleagues at larger institutions, providing advantage benefit to the seemingly negative idea of isolation.

One participant noted how he "embraced isolation. I love that. I get to choose when I go visit my colleagues." The lack of obstruction from departmental members offered participants a 
level of freedom to develop academic programs that would not have been possible in larger programs and/or at larger institutions or at earlier stages of faculty careers. One faculty member described his experience as follows, “It is a marathon per se. I can't play down the political capital that is necessary as well as the cultural capital to be able to do things. A large state-funded research university would have never allowed me to try." Complementing this idea was the ability to experiment or lead new initiatives that was noted by another faculty member,

I had the opportunity to create a program from scratch. I would've never gotten that opportunity. No one in their right mind would have let someone without a formal graduate degree in management and without years of experience in on-line, I have years of experience in business education but not in on-line education, put together an on-line master of arts degree in management. That is one of the things about being in a small place.

While our findings show isolation comes at a cost, there are some unanticipated benefits as well.

\section{Discussion and Implications}

The findings from our research support many of the themes identified in previous research. Namely, our findings reinforce that the work life experiences of rural faculty create tensions as these faculty members adjust to work in a culture significantly different from the one in which they were prepared (Ellis et al., 1999, 2002). In addition, there is a feeling of isolation (Bennefiled 1999; Spall and Norum, 2002), faculty question whether they should stay or leave (Ellis et al., 1999, 2002; Murray 2005), and faculty report wearing many hats (Wolfe and Strange, 2003).

This research diverges from previous studies, however, in key areas. Faculty members in the smaller programs are doing research, often at costs to personal time. But the highly productive faculty in the hinterlands felt they held similar publication and presentation records relative to their peers in research extensive universities, which they perceived to be more resource rich. Additionally, the participants have the added job responsibility of administering their smaller 
programs, including recruitment, enrollment, marketing, and advisement. Despite an active research program and successful program development and administration, issues of legitimacy haunt our participants. Participants had certain cultural anticipation about faculty roles, but the cultural reality of their hinterland university created cognitive dissonance for most of our participants. Both isolation and autonomy within their positions contributed to how these faculty made sense of their roles. Ultimately, the outcomes of this sense-making clustered these participants into three groups: (a) seeking hinterlands; (b) struggling to adjust; and (c) looking to leave. Figure 1 represents how participants made sense of their faculty work roles.

[Insert figure one about here]

Ultimately, the faculty members in our study will opt to stay at their current institutions or attempt to leave. Shifts in the academic labor market (Finnegan 1993) may influence the options open to faculty desiring to move. We argue that culture plays a primary role in the decision to stay or leave. Because aspiring faculty are acculturated during graduate work to anticipate faculty life, when those expectations fail to match the lived experiences, dissonance can result in faculty wanting to leave the mismatched culture. However, some faculty, like many of those in our study, purposely seek out a counter-culture from that in which they were socialized, or they learn to embrace the counter-culture they discover in the hinterlands. The academic identities they are creating inform a counter narrative about faculty work (O’Meara et al., 2008).

This research provides a platform for the voices of faculty often overshadowed by the emphasis on large, more "prestigious" research universities. Huckaby (2007) identified a number of strategies faculty members employ to bridge the disconnect they find in their lived experiences and work expectations. She noted the need to pick the battles to pursue, underscoring how resistance to viewing faculty work as a commodity can create a more authentic faculty work experience. This is 
consistent with the experiences of the faculty members in this study who have come to enjoy and embrace life in the hinterlands.

Faculty participants were quite conscious of their perceived lower status in the pecking order of higher education. Those who were most content with their current position either had experience with living in rural or remote areas allowing them to better understand the culture to which they were going or sought positions with more focus on teaching and interaction with practitioners in the field. While many faculty participants valued the time they spent on research, the differences they made in their student lives and in their personal lives were most critical to them.

Although some of our participants purposefully sought out an institution that would provide different types of experiences, some viewed their current positions as a stepping stone on the way to something else. The faculty members using their current position as a way station initially took whatever job they could get and were trying to make the best of it. These participants felt unsettled. They had a foot in their current institution, but were looking to leave-making their commitment ambiguous. However, the fact remains that many of those seeking to move elsewhere may not have the opportunity to move given the current economic conditions in higher education and the finite number of academic programs in higher education and/or student affairs administration. Some participants even spoke of leaving the faculty ranks and returning to administration in order to leave their current academic environment.

Our findings also indicate that many faculty members in smaller programs and in more remote locations are struggling to create an academic identity that works for them given the norms of the profession and their location. The ideal presented during their graduate work was often based on obtaining a position in a research university with very high research expectations. Despite the intentional choice by some to seek out teaching oriented programs, the learned norm of research productivity still serves as a barometer of success. As a result, our participants noted tensions 
among faculty roles that are inevitable because they were taught a singular model of faulty work that focused on research. These expectations in this research dominant model differ from those of faculty work in smaller, rural programs. Further, this model coupled with the increased ratcheting of expectations for academics in general, contribute to a decreased value of the work of faculty in smaller programs.

The model of research extensive universities creates an expectation for faculty work that is not the reality of the culture in hinterland institutions or the experiences of rural faculty. In the 2009 Academic Ranking of World Universities (Shanghai Ranking Consultancy, 2009), 17 of the top 20 ranked institutions are in the United States. Thus, for ill or good, the higher education model in the United States often provides a template for practices and policies internationally (Rhoades and Sporn, 2002). No matter what context, it is important to understand issues facing faculty, including the nature of anticipatory socialization for the professorate.

There are several implications for the preparation of faculty in the field of higher education administration that add to our growing understanding of the changing roles and rewards for faculty in schools of education (Tierney, 2001). We need to socialize graduate students about the variety of options available for faculty positions and discuss in depth what the tradeoffs are for different programs. From a simple mathematical perspective, only a minority of higher education faculty can teach in the top ten programs in the US, yet faculty are still required at the remaining 184 higher education and student affairs programs. As many new higher education administration faculty members will likely find their first faculty position in programs not at doctoral research extensive universities, doctoral students must be better prepared for and taught about this culture--one that can be very different from that in which they were trained. Moreover, of the 4,391 colleges and universities in the United States, only 199 are categorized as research focused (Carnegie Classification, 2010). According to the Economic Research Service (2010), approximately 50\% of 
county residences are in rural areas, underscoring the need to understand more about faculty working in these regions. Thus, many teaching focused faculty may find similarities between their own experience and that of our participants.

As evident with our participants, however, faculty members make sense of their new roles and adapt and adjust to their new institutional culture, embracing living and working in the hinterlands. The participants in our study have described a different model of faculty work about which those aspiring to the professoriate should be educated. This rural model for faculty is not without its challenges but it does emphasize a more holistic approach to academic work that values teaching and contribution to practice, as well as research. A single model of faculty work life identity does little to support all faculty members, most of whom work in vastly different institutions.

The research outlined here is significant since it affords a view of faculty work rarely explored. Namely, our examination of professional graduate faculty at non-research institutions adds to the tapestry of our understanding of the complex roles of faculty life. The faculty members in our research were adept at border crossing. They successfully navigated the demands of graduate work at research-focused institutions and then moved to a markedly different institutional culture in which success was measured differently.

\section{Conclusion}

In the end, this study shows that culture influences the faculty work experience in smaller, rural programs. The culture in these programs emphasizes and necessitates teaching over research, time dedicated to practice, and interdisciplinary collaborations. Work roles are based on lived experiences in smaller areas, but began with socialization in doctoral programs. While new faculty may have the requisite research skills for their positions, for those hired at institutions other than doctoral research extensive universities, graduate school may not have fully prepared them for other 
job demands. Faculty socialization (Austin 2002; Wulfe and Austin, 2004) and new faculty concerns regarding requirements in the professoriate (Austin 2003; Menges 1999; Sorcinelli 2002) underscore how graduate students form impressions and anticipations regarding a faculty career. The research culture in which most faculty members are trained affords a limited view of faculty life.

Yet, the current acculturation and socialization of aspiring academics tends to exclude any counter-narratives of culture beyond the research extensive university. While not all faculty culture in rural areas is similarly experienced, our participants state that it is markedly different than the current socialized norm. Our participants showed that they can endure the mismatch between their cultural anticipation of what faculty work should be and their lived experiences in the hinterlands. However, we should not be satisfied with this.

Instead, these findings should serve as a clarion call to socialize and train future faculty about what it means to work in a rural location as opposed to the type of departments in which they are graduate students in predominantly research extensive institutions. This type of professional development will aid in making cultural anticipation and cultural reality more closely aligned. In addition, faculty development, including orientation, should be improved to support new faculty in rural colleges, like those in this study. This orientation to the college should include clarification of institutional values and norms and provide opportunities to strategize how to blend teaching, research, and practice in ways that lead to a positive tenure decision.

In general, we should look critically at the ratcheting up of expectations for promotion and tenure and mission drift (Rhoades 2009). This change in tenure expectations is a concern at all institutions, but may be especially acute at institutions like those where the participants in our study work since often they have fewer human and financial resources. Further research should explore how faculty view their position after being on their rural campus for a number of years. In 
particular, do those faculty members struggling to adjust or desiring to leave have a change in

perspective over time? Do those who desire to leave and do make a move to another institutional

type or location find an improved experience or did the grass just appear greener over the other side

of the fence? A final point to make is that the faculty members in this study are confident,

productive, academics who are making a difference in the lives of their students and communities.

Their work should be recognized for its own value and not measured against a socially constructed

norm based on a research life.

\section{References}

Aldersley, S. F. 1995. Upward drift is alive and well: Research/doctoral model still attractive to institutions. Change 27, no. 5: 50-56.

Austin, A. E. 2002. Preparing the next generation of faculty: Graduate school as socialization to the academic career. Journal of Higher Education 73: 94-122.

Austin, A. E. 2003. Creating a bridge to the future: Preparing new faculty to face changing expectations in a shifting context. Review of Higher Education 26: 119-144.

Bennefield, R. M. 1999. Tales from the boondocks. Black Issues in Higher Education 16, no. 18: 24-29.

Bhandari, R., and Laughlin, S. (Eds.) 2009. Higher education on the move: New developments in global mobility. New York: The Institute of International Education.

Boyer, E. L. 1997. Scholarship reconsidered: Priorities of the professoriate. San Francisco: Jossey-Bass.

Carnegie Classification. 2010. The Carnegie Foundation for the Advancement of Teaching. Summary tables: Basic classification. Retrieved December 21, 2010 http://classifications.carnegiefoundation.org/summary/basic.php

Clark, B. R. 1987. The academic life: Small worlds, different worlds. Lawrenceville, NJ: Princeton University Press.

Creswell, J. W. 1998. Qualitative inquiry and research design: Choosing among five traditions. Thousand Oaks, CA: Sage.

Denizon, N. K., and Lincoln, Y. S. 2000. Handbook of qualitative research. Thousand Oaks, CA: Sage Publication.

Economic Research Service. 2010. Measuring rurality: What is rural? Retrieved December 21, 2010 http://www.ers.usda.gov/Briefing/Rurality/whatisrural/

Ellis, B., Boxall, D., Dollard, M., and Sawyer, J. 1999, December. Swings and roundabouts: Working as a rural academic. Paper presented at the Annual National Research Forum of the Australian Rural Education Research Association, Inc., Melbourne, Victoria.

Ellis, B., Sawyer, J., Dollard, M., and Boxall, D. 2002. Working as rural academics. Education in Rural Australia 12, no. 1: 43-50.

Fairweather, J. 1996. Faculty work and public trust: Restoring the value of teaching and public service in American academic life. Boston: Allyn \& Bacon. 
Field, K. 2006. The Spellings report. Uncertainty greets report on colleges by U.S. panel. The Chronicle of Higher Education 53, no. 2: A1.

Finnegan, D. E. 1993. Segmentation in the academic labor market: Hiring cohorts in comprehensive universities. The Journal of Higher Education 64, no. 6: 621-656.

Hazelkorn, E. 2009. Rankings and the battle for world-class excellence: Institutional strategies and policy choices. Higher Education Management and Policy 21, no. 1: 55-76.

Ganga, D., and Scott, S. 2006. Cultural "insiders" and the issue of positionality in qualitative migration research: Moving "across" and moving "along" researcher-participant divides. ForumQualitative Sozialforschung/Forum: Qualitative Social Research 7, no. 3, Art. 7., http://nbn-resolving.de/urn:nbn:de:0114-fqs060379.

Geertz, C. 1993. The interpretation of cultures. London: Fontana Press.

Huckaby, F. M. 2007. A conversation on practices of self within relations of power: For scholars who speak dangerous truths. International Journal of Qualitative Students in Education, 20, no. 5: 513-529.

Labi, A. 2008. Obsession with rankings goes global. Chronicle of Higher Education 55, no. 8: A27.

Kvale, S. 1996. Interviews: An introduction to qualitative research interviewing. Thousand Oaks, CA: Sage.

Menges, R. (Ed.) 1999. Faculty in new jobs: A guide to settling in, becoming established, and building institutional support. San Francisco, CA: Jossey-Bass.

Murray, J. P. (2005). Meeting the needs of new faculty at rural community colleges. Community College Journal of Research and Practice 29: 215-232.

Rauch, A. 2005, April 1. Great work. You're fired. The Chronicle Review, Section B of The Chronicle of Higher Education, p. B15.

Rhoades, G. 2009. What we do to our young. Academe 95, no. 3. Retrieved from http://www.aaup.org/AAUP/pubsres/academe/2009/MJ/col/ftgs.htm

Rhoades, G., and Sporn, B. 2002. Quality assurance in Europe and the US: Professional and political economic framing of higher education policy. Higher Education 43, no. 3: 355-390. doi: 10.1023/A:1014659908601

Rubin, H. J., and Rubin, I. S. 1995. Qualitative interviewing: The art of hearing data. Thousand Oaks, CA: Sage.

Shanghai Ranking Consultancy. 2009. Academic ranking of world universities -2009 . Retrieved from: http://www.arwu.org/ARWU2009.jsp

Sorcinelli, M. D. 2002. New conceptions of scholarship for a new generation of faculty members. New Directions for Teaching and Learning 90, 41-48.

Spall, S. L., and Norum, K. E. 2002, April. Forming and reforming identity: Learning our work in higher education. Paper presented at the AERA Annual Conference, New Orleans, LA.

Tierney, W. G. (Ed.) 2001. Faculty work in schools of education: Rethinking roles and rewards for the Twenty-first Century. Albany: State University of New York Press.

Toma, J. D. 2009. Positioning for prestige in American higher education: Case studies of strategies at four public institutions toward "getting to the next level." Los Angeles: Center for Enrollment Research, Policy, and Practice. Retrieved from: http://www.usc.edu/programs/cerpp/docs/CERPPSummaryPaperToma.doc

VanderStaay, S. L. 2005, June 10. In the right direction. The Chronicle of Higher Education, p. B5. Wilson, V. A. 2000, November. Making the move: The transition from graduate student at a Ph.D.granting university to new faculty member at a small, private, liberal arts college. Paper presented at the Annual Meeting of the Mid-South Educational Research Association, Bowling Green, KY. 
Wolfe, J. R., and Strange, C. C. 2003. Academic life at the franchise: Faculty culture in a rural twoyear branch campus. The Review of Higher Education 26, no. 3: 343-362.

Wulff, D., and Austin, A. E. 2004. Paths to the professoriate. San Francisco: Jossey-Bass. 